\title{
Costa Rica sin Fronteras
}

Pensar en Movimiento:

Revista de Ciencias del Ejercicio y la Salud

ISSN 1659-4436

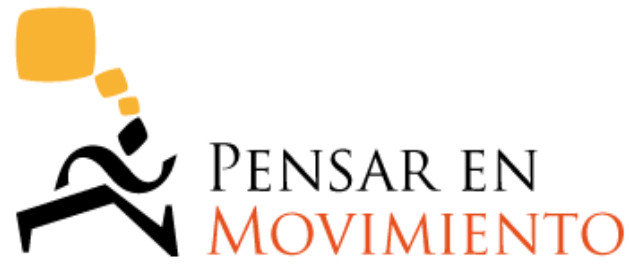

Vol. 19, No.2, pp. 1 - 2

Abre $1^{\circ}$ de julio, cierra 31 de diciembre, 2021

\section{COSTA RICA SIN FRONTERAS \# 24}

En esta sección se publican los resúmenes en español de artículos que han sido publicados por investigadoras/es de universidades costarricenses en otras revistas en el mundo, con su debida referencia al trabajo original, y con una breve explicación de dónde se realizó la investigación. Los artículos originales han sido publicados en otros idiomas; las revistas tienen consejo editorial y manejan un proceso de revisión por pares.

Los resúmenes corresponden a estudios relacionados con las ciencias del ejercicio y la salud, que se conforman a los criterios generales de la revista, esto es, se trata de "... estudios experimentales o que hagan recomendaciones concretas para solucionar problemas o preguntas relevantes (...) trabajos originales o de meta-análisis." Solicitamos a quienes hayan publicado este tipo de trabajos en otros idiomas que no los hagan saber, para incluir sus resúmenes en futuras entregas de esta sección.

\section{Luis Fernando Aragón V., Ph.D., FACSM \\ Director, PENSAR EN MOVIMIENTO}




\title{
EL CONOCIMIENTO DE LA PÉRDIDA DE LÍQUIDOS NO AFECTA LA PERCEPCIÓN DE SED DURANTE EL EJERCICIO EN CALOR: UN ESTUDIO CRUZADO Y DOBLE CIEGO
}

\author{
Capitán-Jiménez, C. \& Aragón-Vargas, L.F. (2021). Awareness of Fluid Losses Does Not \\ Impact Thirst during Exercise in the Heat: A Double-Blind, Cross-Over Study. \\ Nutrients, 13, 4357. doi: https://doi.org/10.3390/nu13124357
}

\begin{abstract}
Antecedentes: La sed se ha utilizado como indicador de deshidratación, sin embargo, esta percepción podría verse afectada por la información recibida relacionada con las pérdidas de líquidos. El propósito de este estudio fue identificar si la conciencia de la pérdida de agua podría afectar la percepción de la sed durante el ejercicio en el calor. Métodos: Once hombres participaron en dos sesiones con orden aleatorio, recibiendo información verdadera o falsa de sus pérdidas de líquidos cada 30 minutos. La percepción de la sed (PS), la deshidratación real, la llenura y la percepción del calor se midieron cada 30 minutos durante el ejercicio intermitente hasta que se logró una deshidratación de 4\% de la masa corporal (MC). Después del ejercicio ingirieron agua ad libitum durante 30 minutos. Resultados: La MC, la PS y el nivel de hidratación antes del ejercicio no fueron diferentes entre sesiones ( $p>0.05)$. A medida que la deshidratación aumentaba durante el ejercicio, la PS aumentó significativamente $(p=0,001)$, pero fue igual para ambas sesiones $(p=$ $0,447)$. La ingesta de agua después del ejercicio fue casi idéntica $(p=0,949)$ entre sesiones. Conclusión: En este estudio, la sed fue un buen indicador de las necesidades de líquidos durante el ejercicio en el calor cuando no se ingirieron líquidos, independientemente de recibir información verdadera o falsa sobre la pérdida de agua.
\end{abstract}

Palabas clave: ingesta voluntaria de líquido, deshidratación, percepción de la sed.

La revista Nutrients presenta un Factor de Impacto de 5.719 para el año 2020 según su propia página. Este estudio se realizó en el Centro de Investigación en Ciencias del Movimiento Humano (CIMOHU) de la Universidad de Costa Rica, Sabanilla, Costa Rica, como parte del proyecto de investigación VI-838-B4-309 "Sed, hidratación y rendimiento físico". Colaboradora: Catalina Capitán Jiménez, actualmente en la Universidad Hispanoamericana de Costa Rica. 